\title{
ANALISIS DAN PERANCANGAN SISTEM INFORMASI PENGUPAHAN KARYAWAN OUTSOURCING PADA PT MULTI MANDIRI BERBASIS WEB
}

\author{
${ }^{1}$ Rinah Efriana, ${ }^{2}$ Rini Malfiany \\ E-mail : ${ }^{1}$ rinah_efriana@yahoo.co.id, ${ }^{2}$ rini@rosma.ac.id
}

\begin{abstract}
Abstrak
Pengupahan karyawan outsourcing pada PT Multi Mandiri belum maksimal sehingga dapat menyebabkan lamanya proses pengupahan dalam satu periode berdasarkan pengupahan perminggunya sering terjadi kesalahan-kesalahan akibat proses pencatatan manual yang selama ini dilakukan. Maka dari itu perlu dibangun sistem informasi pengupahan karyawan outsourcing agar dapat menyajikan informasi secara cepat dan akurat serta mengurangi terjadinya kesalahankesalahan dalam memproses pengupahan karyawan outsourcing. Metode penelitian yang digunakan adalah metode SDLC dengan model waterfall dimulai dari analisis dan observasi terhadap sistem yang berjalan di perusahaan. Kemudian dari data yang ada dilakukan perancangan sistem informasi pengupahan karyawan outsourcing yang disesuaikan dengan kebutuhan perusahaan. Sistem informasi pengupahan karyawan outsourcing berbasis web yang dirancang dapat mengelola data berdasarkan data absen dan data lembur disetiap harinya, untuk mengurangi pencatatan manual pengupahan karyawan outsourcing agar data yang disajikan sesuai dengan yang diharapkan dan dapat mengurangi kesalahan yang biasa terjadi ketika menggunakan sistem yang lama.
\end{abstract}

Kata kunci : pengupahan karyawan outsourcing, outsourcing, pengupahan, web

\section{Abstract}

Wages of outsourced employees in PT Multi Mandiri have not been maximal so that it can cause the length of the remuneration process in one period based on the remuneration of the week often occur errors due to manual recording process that has been done. Therefore it is necessary to build an outsourced employee wage information system in order to present information quickly and accurately and reduce the occurrence of errors in the process of wage employee outsourcing. The research method used is SDLC method with waterfall model starting from analysis and observation to system running in company. Then from the existing data is done information system design of outsourced employee wages tailored to the needs of the company. Wage-based outsourced employee information systems designed to manage data based on absent data and overtime data on a daily basis, to reduce manual remuneration of outsourced employees in order to present data as expected and reduce errors commonly used when using the old system.

Keywords: outsourced employee outsourcing, outsourcing, remuneration, web 


\section{Pendahuluan}

Perkembangan tehnologi pada era yang serba cepat seperti saat ini, keterlambatan dalam menyajikan informasi yang dibutuhkan, akan menyebabkan informasi tersebut tidak relevan bagi penggunanya terutama dalam hal bisnis, seperti perusahaan yang bergerak di bidang manufaktur. PT Multi Mandiri merupakan salah satu perusahaan yang bergerak di bidang manufaktur berdiri sejak 12 September 2013 dan memproduksi kebutuhan rumah tangga yang terletak di daerah Karawang Timur. PT Multi Mandiri mempunyai 1812 karyawan yang terdiri atas karyawan staff, non staff dan outsourcing dengan meliputi karyawan staff 108 , non staff 1454 dan 250 karyawan outsourcing. PT Multi Mandiri memiliki dua tipe pemberian upah pada karyawan, yang pertama penggajian pada karyawan staff dan non staff, yang kedua pengupahan pada karyawan outsoucing. Perbedaan di antara keduannya adalah untuk penggajian akan dibayarkan pada setiap akhir bulan dan untuk pengupahan akan dibayar pada setiap akhir minggu.

Pengolahan penggajian karyawan menggunakan sistem System Application and Product in Data Processin (SAP), kecuali pengupahan pada karyawan outsourcing, pengolahan upah karyawan outsourcing tersebut masih menggunakan Microsoft Excel 2010. Proses pengolahan upah tersebut admin payroll mengumpulkan rekap absen dan data lembur karyawan outsourcing yang diberikan oleh pengawas masing-masing bagiannya.

Upah karyawan outsourcing sering terjadinya kesalahan dalam pengelolahannya. Hal ini disebabkan karena pengolahan upah masih menggunakan Microsoft Excel 2010. Mulai dari pengelolaan upah pokok yang diinput ke dalam Microsoft excel dan proses pemotongan $\mathrm{PPh}$ 23. Pemotongan $\mathrm{PPH} 23$ adalah pajak yang dikenakan pada penghasilan atas modal, penyerahan jasa, atau hadiah dan penghargaan. Pemotongan $\mathrm{PPh} 23$ tersebut dibebankan kepada masing-masing karyawan outsourcing tetapi pemotongan $\mathrm{PPh}$ tersebut atas nama CV/Kontraktor yang bersangkutan. Sehingga dalam pengolahan pengupahan membutuhkan waktu yang cukup lama. Saat ini pengolahannya menggunakan Microsoft excel 2010, admin akan lembur pada hari Jumat hingga pukul 22.00 karena setiap hari Sabtu pengupahan karyawan outsourcing harus dibagikan lengkap dengan slip upah.

Pengupahan merupakan salah satu pokok penting bagi pekerja dan upah sudah menjadi ketetapan yang harus dibayarkan oleh sebuah perusahaan atau pengusaha kepada karyawannya. Dengan upah diharapkan karyawan bisa termotivasi meningkatkan kinerjanya dalam berproduksi, sehingga dapat memajukan perusahaan itu sendiri.

Peneliti mencoba untuk membuat aplikasi yang bermanfaat, sederhana, dan mudah digunakan. Oleh karena itu peneliti membuat judul penelitian yaitu "Analisis dan Perancangan Sistem Informasi Pengupahan Karyawan Outsourcing Berbasis Web Pada PT Multi Mandiri”.

Aplikasi ini ditujukan untuk admin payroll sehingga memudahkan untuk penginputan upah karyawan outsourcing. Aplikasi berbasis web ini akan lebih mudah jika suatu saat ada pembaharuan aplikasi hanya dengan dengan server, maka aplikasi akan terbaharui.

\section{Tinjauan Pustaka}

\section{Analisis Sistem}

Menurut Yakub (2012:142), "Analisis sistem dapat diartikan suatu proses untuk memahami sistem yang ada dengan menganalisa jabatan dan uraian tugas (business user), Proses bisnis (business process), ketentuan atau aturan (business rule), masalah dan solusinya (business and problem), dan rencana-rencana perusahaan (business plan)".

\section{Perancangan}

Menurut Mohamad Subhan (2012:109), "Perancangan adalah proses pengembangan spesifikasi baru berdasarkan rekomendasi hasil analisis sistem".

\section{Sistem}

Menurut Tata Sutabri (2012:6), "pada dasarnya sistem adalah sekelompok unsur yang erat hubungannya satu dengan yang lain, yang 
berfungsi bersama-sama untuk mencapai tujuan tertentu".

\section{Informasi}

Menurut Yakub (2012:8), "Informasi adalah data yang diolah menjadi bentuk yang lebih berguna bagi penerimanya”.

\section{Sistem Informasi}

Menurut Alter dalam Abdul Kadir (2014:9), "Sistem Informasi adalah kombinasi antar prosedur kerja, informasi, orang, dan teknologi informasi yang diorganisasikan untuk mencapai tujuan dalam sebuah organisasi”.

\section{Outsourcing}

Menurut Adi Mujianto (2014:8), "Outsoucing merupakan pedelegasian operasi dan manajemen haian dari suatu proses bisinis kepada pihak luar (perusahaan yang menyedia jasa/outsourcing)".

\section{Upah/Gaji}

Menurut Edwin B. Flippo, "upah adalah harga untuk jasa-jasa yang telah diberikan oleh seseorang kepada orang lain".

Menurut Prof. Dr. FJHH Van Der Ven, "upah adalah tujuan objektif ekonomi".

Menurut Dewan Penelitian Pengupahan Nasional, "upah adalah suatu penerimaan sebagai suatu imbalan dari pemberi kerja kepada penerima kerjaa untuk suatu pekerjaan atau jasa yang telah dan akan dilakukan, berfungsi sebagai jaminan kelangsungan kehidupan yang layak bagi kemanusiaan dan produksi yang dinyatakan dan dinilai dalam bentuk uang yang ditetapkan menurut suatu persetujuan, UU, Peraturan, dan dibayarkan atas suatu dasar perjanjian kerja antara pemberi kerja dan penerima kerja".

Perbedaan prinsip antara upah dan gaji menurut Jimmy L Gaol (2014), adalah sebagai berikut :

"Upah adalah pembayaran itu tidak terikat pada waktu, bias harian, mingguan, bulanan. Dibayar jika telah berprestasi".

"Gaji adalah Pembayaran tiap bulan. Ada atau tidak ada prestasi, tetap dibayar setiap bulan".

\section{Karyawan}

Menurut Kamus Besar Bahasa Indonesia (KBBI), "karyawan adalah orang yang bekerja pada suatu lembaga (kantor, perusahaan, dan sebagainya) dengan mendapatkan gaji (upah), pegawai, pekerja".

\section{PPh 23}

Menurut Dirjen Pajak, "Pajak Penghasilan Pasal 23 (PPh Pasal 23) adalah pajak yang dikenakan pada penghasilan atas modal, penyerahan jasa, atau hadiah dan penghargaan, selain yang telah dipotong PPh Pasal 21". Umumnya penghasilan jenis ini terjadi saat adanya transaksi antara dua pihak. Pihak yang menerima penghasilan atau penjual atau pemberi jasa akan dikenakan PPh Pasal 23. Pihak pemberi penghasilan atau pembeli atau penerima jasa akan memotong dan melaporkan PPh Pasal 23 tersebut kepada kantor pajak".

\section{Pemotongan PPh Pasal 23}

Pemotongan PPh Pasal 23 menurut Undang-Undang Pajak Penghasilan adalah badan pemerintah, subjek pajak badan dalam negeri, penyelenggara kegiatan, bentuk usaha tetap, atau perwakilan perusahaan luar negeri lainnya. Namun pada pasal 23 ayat (3) Wajib Pajak orang pribadi dalam negeri dapat ditunjuk sebagai pemotongan PPh 23. Orang Pribadi yang dapat ditunjuk sebagai pemotong PPh Pasal 23 yakni Akuntan, Arsitek, Dokter, Notaris, Pejabat Pembuat Akte Tanah (PPAT) kecuali PPAT tersebut adalah camat, pengacara, dam konsultan, yang melakukan pekerjaan bebas, Orang pribadi yang menjalankan usaha yang menyelenggarakan pembukuan.

Objek Pemotongan PPh Pasal 23 yang dipotong oleh Wajib Pajak Orang Pribadi Dalam Negeri Tertentu yang ditunjuk menjadi Pemotong PPh Pasal 23 hanya terkait transaksi atas sewa dan penghasilan lain sehubungan dengan penggunaan harta, kecuali sewa tanah dan/atau bangunan.

Tarif yang dikenakan nilai Dasar Pengenaan Pajak (DPP) atau jumlah bruto dari penghasilan. Ada dua jenis tarif yang dikenakan pada penghasilan yaitu $15 \%$ dan $2 \%$, tergantung dari objeknya. Berikut ini adalah daftar tarif dan objek PPh Pasal 23 : 
Tarif $15 \%$ dari jumlah bruto atas :

Dividen, kecuali pembagian dividen kepada orang pribadi dikenakan final, bunga dan royalti; Hadiah dan penghargaan, selain yang telah dipotong PPh Pasal 21;

Tarif 2\% dari jumlah bruto atas sewa dan penghasilan lain yang berkaitan dengan penggunaan harta kecuali sewa tanah dan/atau bangunan.

Tarif $2 \%$ dari jumlah bruto atas imbalan jasa teknik, jasa manajemen, jasa kontruksi dan jasa konsultan.

Tarif $2 \%$ dari jumlah bruto atas imbalan jasa lainnya.

Pemotongan PPh 23 dilakukan oleh badan usaha dengan ketentuan jika badan usaha tersebut memiliki NPWP, maka PPh 23 akan dikenakan potongan $2 \%$ dari jumlah yang didapat, sedangkan badan usaha yang tidak memiliki NPWP maka akan dikenakan potongan PPh 23 sebesar $4 \%$.

\section{Metodologi Penelitian}

Penelitian ini menggunakan metode pengembangan sistem yaitu System Development Life Cycle (SDLC). SDLC merupakan metodologi klasik yang digunakan untuk mengembangkan, memelihara, dan menggunakan sistem informasi dan metodologi ini mencakup sejumlah fase atau tahapan. (Kadir 2014).

\section{ANALISIS DAN PERANCANGAN SISTEM}

Prosedur sistem yang berjalan

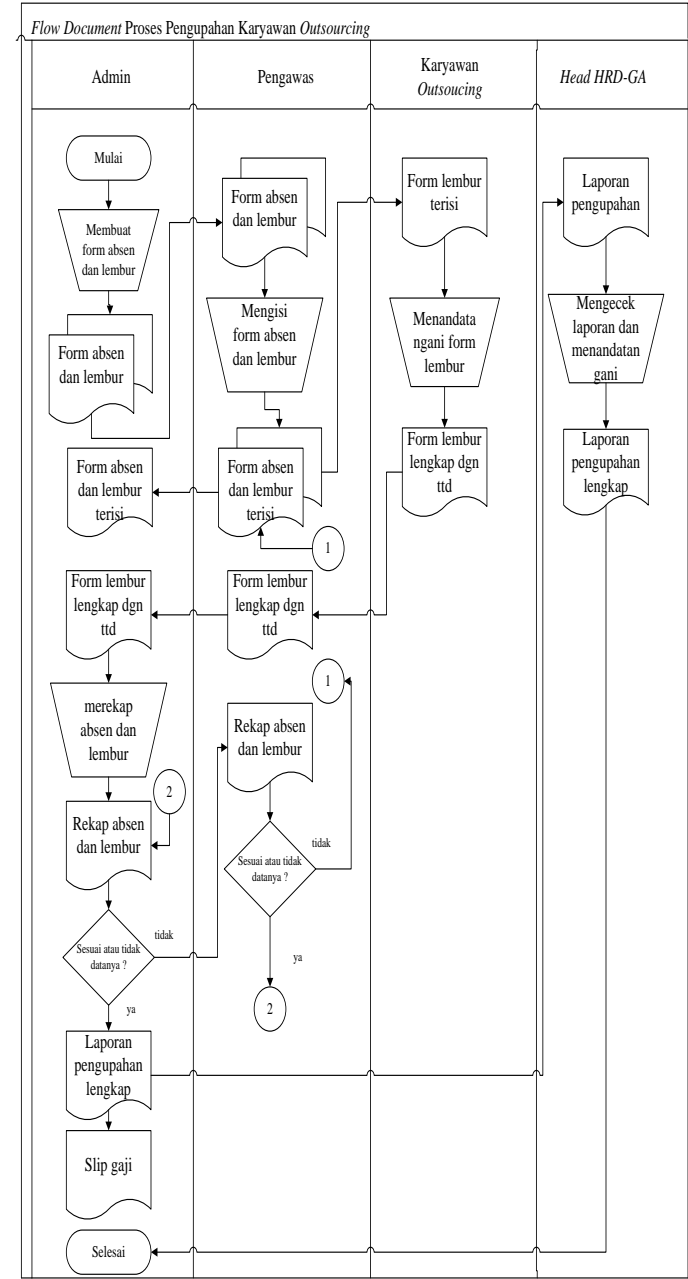

Gambar 1. Flow Document Proses Pengupahan Karyawan Outsourcing Usulan sistem yang baru 


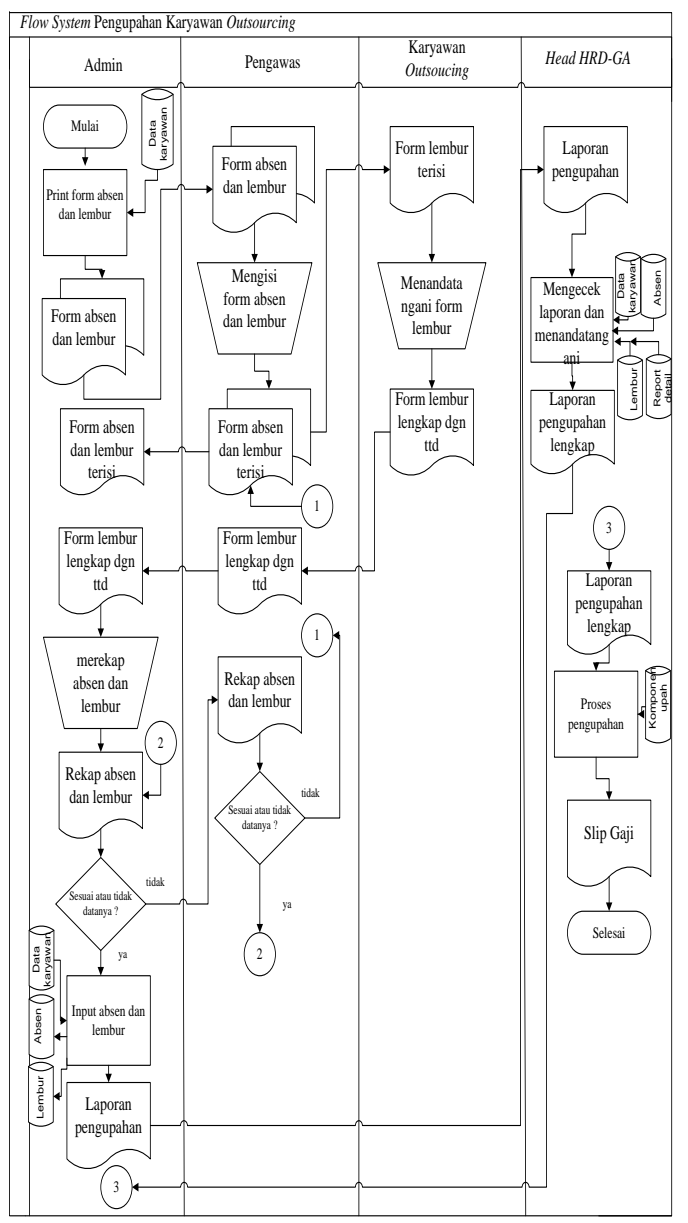

Gambar 2. Flow System Pengupahan Karyawan Outsourcing

\section{Rancangan Proses}

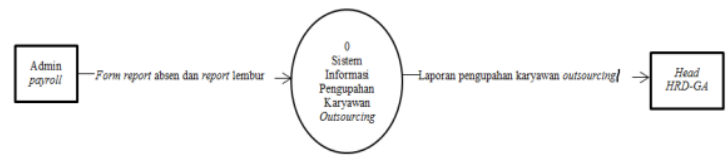

Gambar 3. Diagram konteks Sistem Informasi Pengupahan Karyawan Outsourcing

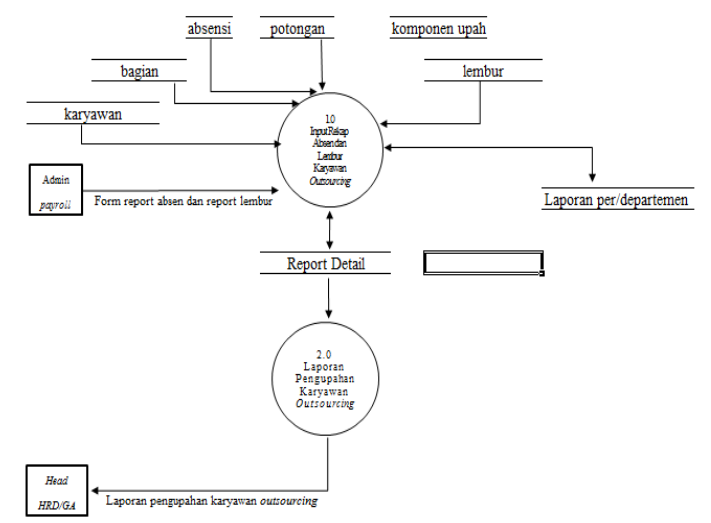

Gambar 4. Diagram Overview Sistem Informasi Pengupahan Karyawan Outsourcing

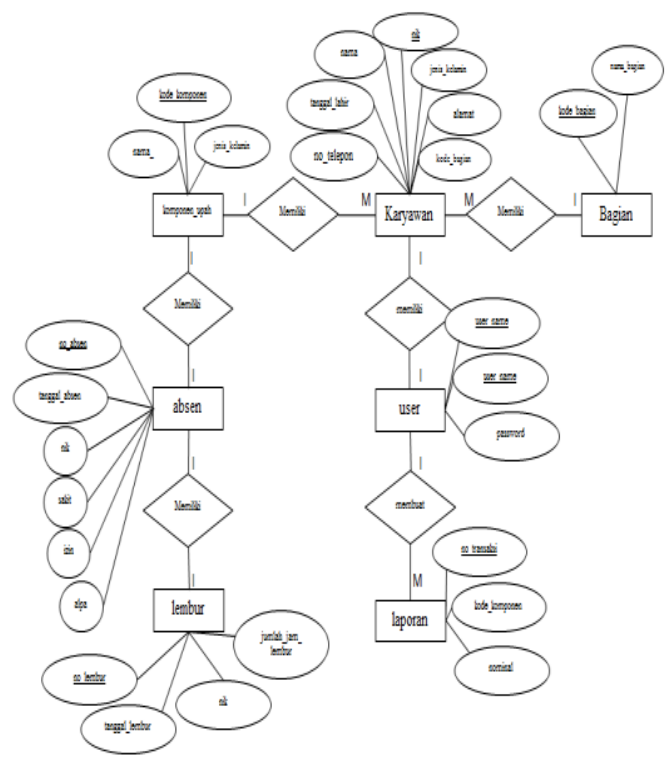

Gambar 5. Entity Relationship Diagram (ERD) Sistem Informasi Pengupahan Karyawan Outsourcing 


\section{Implementasi System}

\section{Form Login}

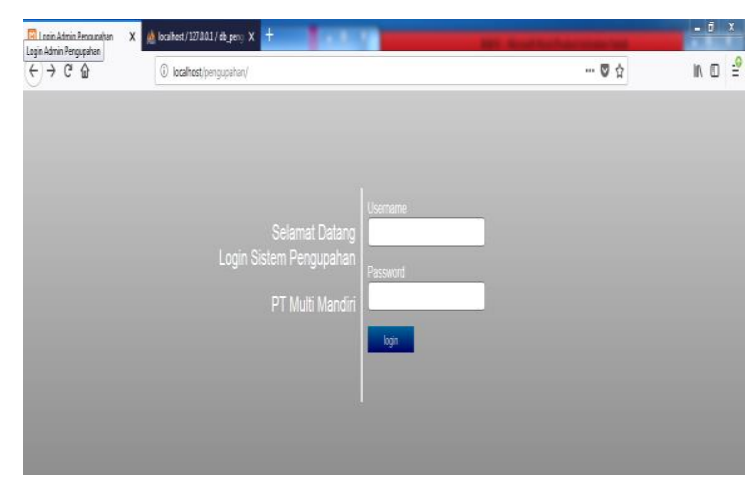

Gambar 6. Tampilan Form Login Sistem

\section{Form Input Data Karyawan}

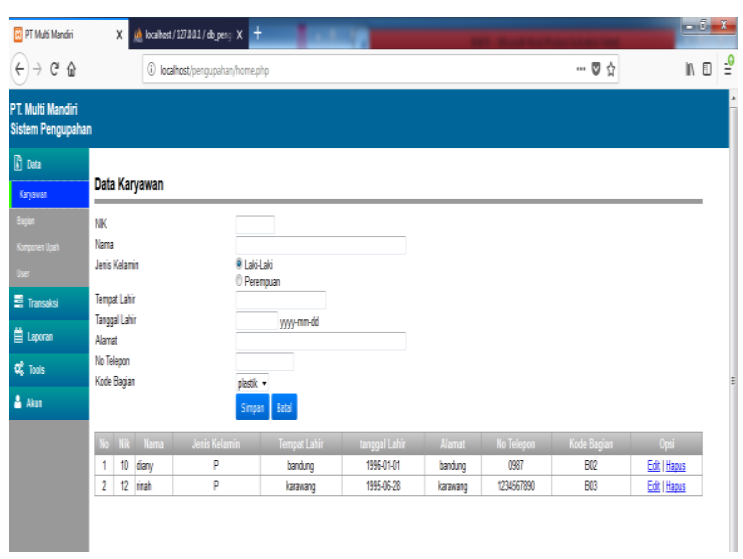

Gambar 7. Tampilan Form Input Data Karyawan

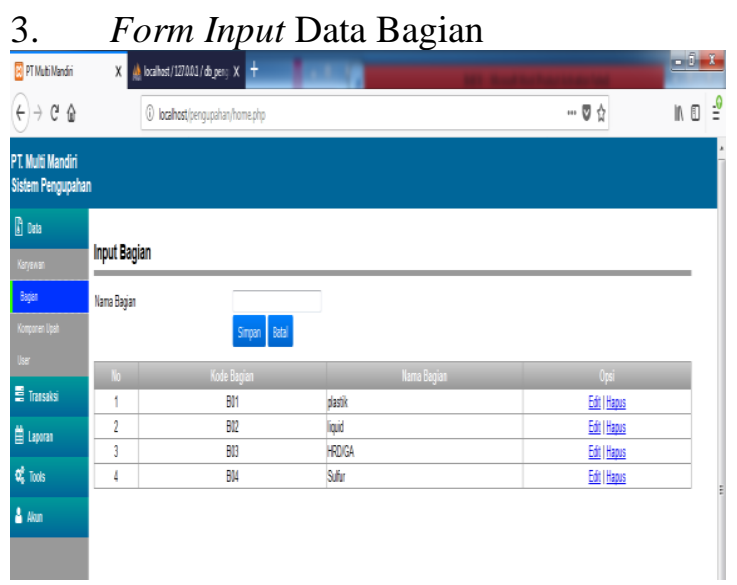

Gambar 8. Tampilan Form Input Data Bagian

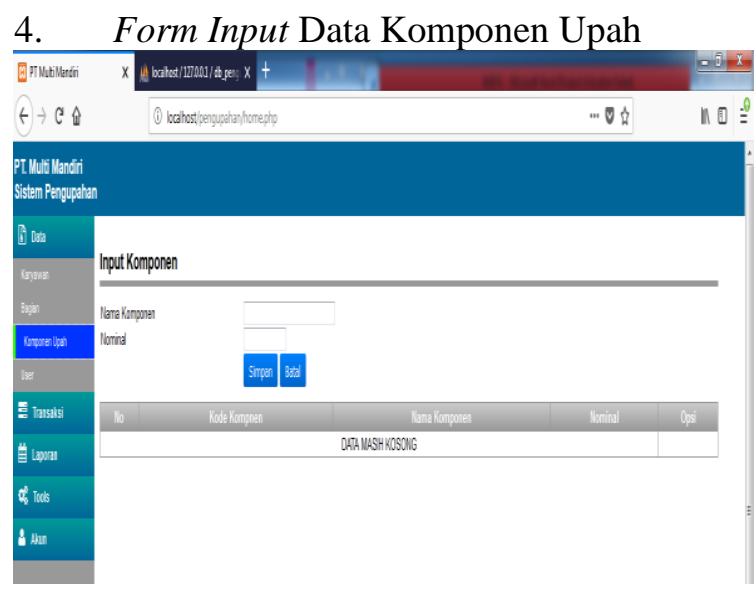

Gambar 9. Tampilan Form Input Data Komponen Upah

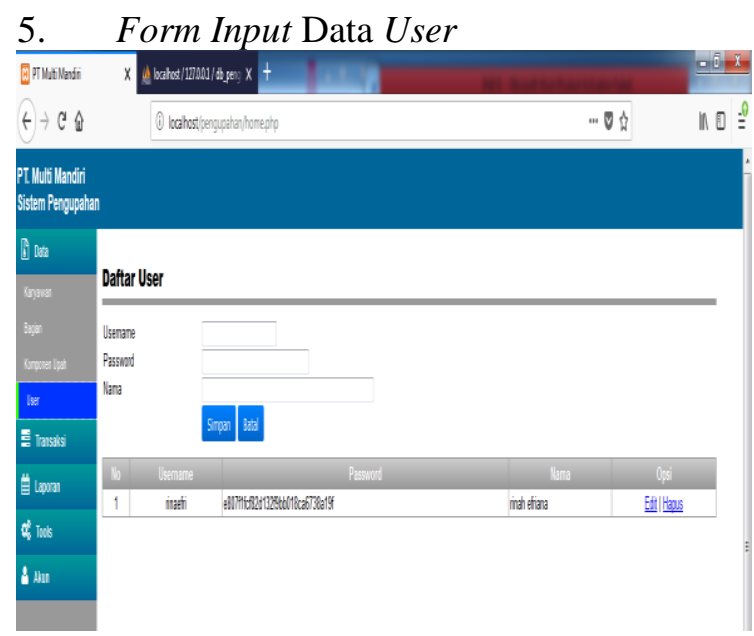

Gambar 10. Tampilan Form Input Data User

6. Form Input Data Lembur

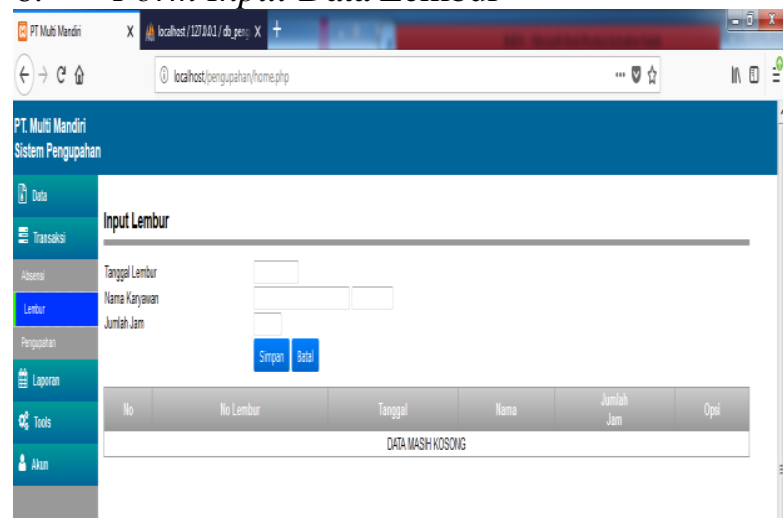

Gambar 11. Tampilan Form Input Data Lembur 


\section{Form Input Data Pengupahan}

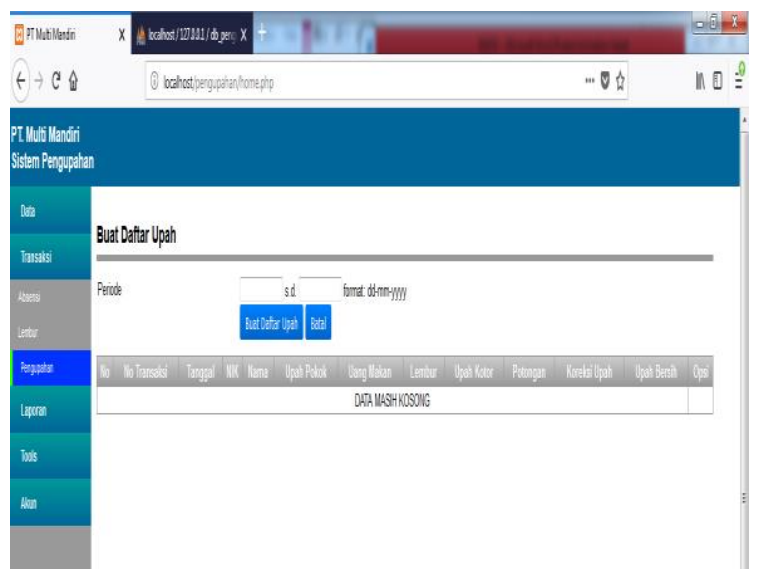

Gambar 12. Tampilan Form Input Data Pengupahan

\section{Form Input Data Koreksi Upah}

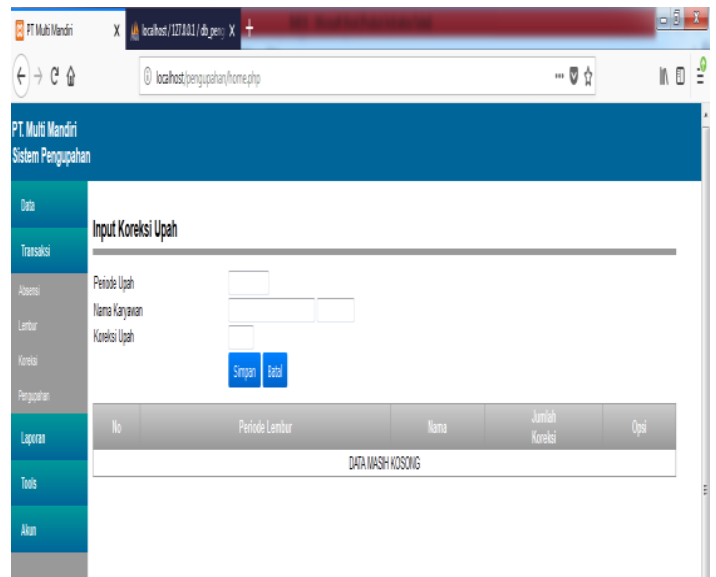

Gambar 13. Tampilan Form Input Data Koreksi Upah

\section{Form Menampilkan Daftar Upah}

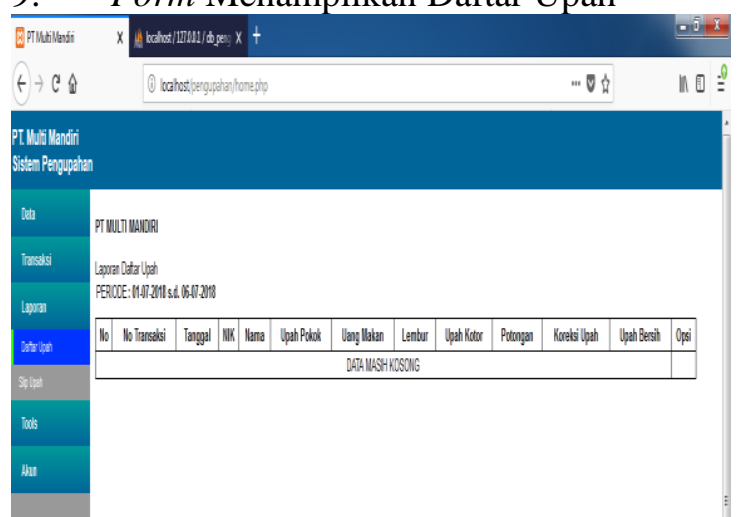

Gambar 14. Tampilan Form Menampilkan Daftar Upah

\section{Form Menampilkan Slip Upah}

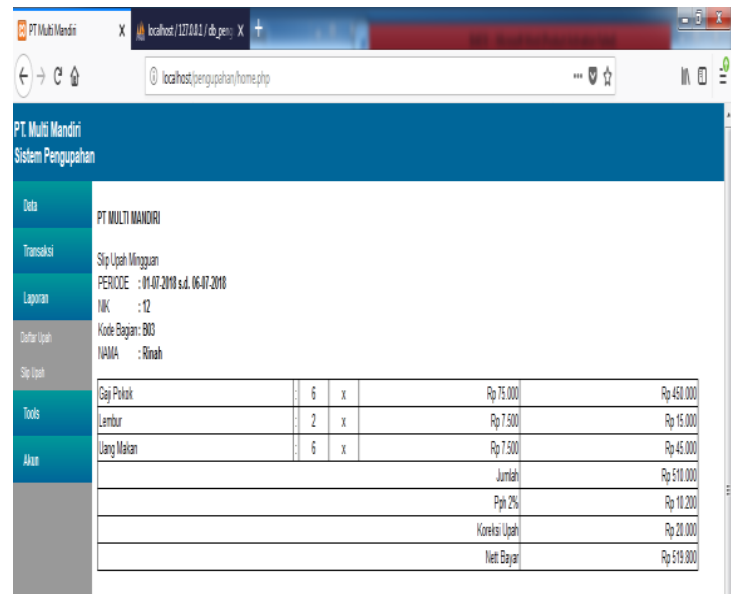

Gambar 15. Tampilan Form Menampilkan Slip Upah

\section{Database Bagian}

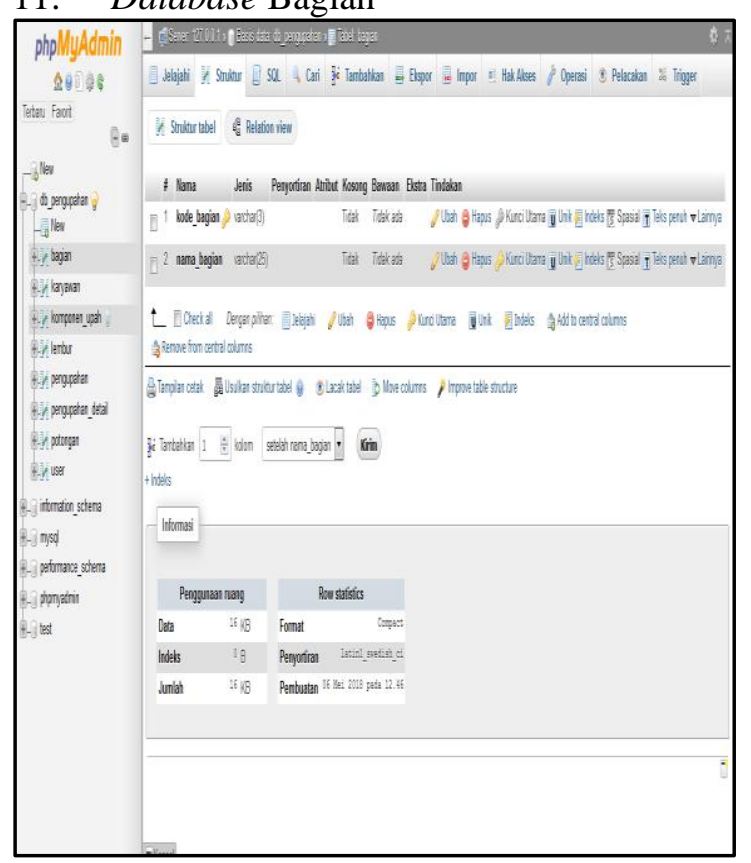

Gambar 16. Tampilan Database Bagian

\section{Kesimpulan dan Saran}

\section{Kesimpulan}

Berdasarkan hasil penelitian yang meliputi data-data pembuatan laporan penelitian, maka kesimpulannya adalah aplikasi tersebut dapat :

- menyajikan data dengan cepat dan akurat, 
- mempermudah admin $H R G / G A$ dalam memproses pengupahan karyawan outsourcing,

- memiliki pengelolaan data yang baik, mempermudah dalam pencarian data karyawan outsourcing.

\section{Saran}

Berdasarkan hasil analisis yang dilakukan, maka peneliti mencoba memberikan saran yang dengan harapan berguna bagi pembaca. Adapun saran-sarannya adalah sebagai berikut :

- $\quad$ Sistem Pengupahan Karyawan Outsourcing Berbasis Web ini dapat dikembangkan dengan menambahkan desain tampilan lainnya agar lebih baik lagi dan menarik, seperti menampilkan profil perusahaan atau tampilan pengupahan yang lainnya.

- Diharapkan adanya pengembangan sistem agar program yang dirancang berfungsi secara optimal dan dapat membantu admin untuk mengelola pengupahan karyawan, khususnya karyawan outsourcing.

\section{Daftar Pustaka}

Abdul Kadir (2014). Pengenalan Sistem Informasi Edisi Revisi. Yogyakarta. Andi Offset.

Achmad, Solihin. (2010). MySQL 5 Dari Pemula Hingga Mahir. Jakarta: Universitas Budi Luhur.

Arief, Rudianto. (2011). Pemrograman Web Dinamis menggunakan PHP dan MySQL. Yogyakarta. Andi.

Arnidar dan Ibnu (2016). Sistem Informasi Kepegawaian Outsourcing Berbasis Web pada PT Supraco Indonesia Jakarta. ISBN: 975-602-72850-3-3. SNIPTEK 2016

Azhar, Susanto. (2013). Sistem Informasi Akuntansi. Bandung. Lingga Jaya.

Black, Rex. (2015). Advanced Software Testing 2nd Edition. USA: Library of Congress Cataloging-in-Publication Data.
Bungin, Burhan. (2011). Penelitian Kualitatif. Jakarta: Kencana Predana Media Group

Cosmas Eko, Joni Eka dan Fergyanto E. (2017). Perancangan Sistem Informasi Penggajian Terintegrasi Berbasis Web (Studi Kasus di Rumah Sakit St.Elisabeth). ISSN Print 2460-3465, ISSN Online 2476-8812. Vol. 3 No.2, Hal 225-232.

Fathansyah. (2012). Basis Data (Edisi Revisi). Bandung: Informatika.

Hanif, al fatta (2007). Analisis \& Perancangan Sistem Informasi. Yogyakarta : CV Andi Offset

Hartono, Bambang. 2013. Sistem Informasi Manajemen Berbasis Komputer. Jakarta: Rineka Cipta.

Indrajani. 2011: Perancangan Basis Data All in 1. Jakarta: Alex Media Komputindo.

Jogiyanto, (2010). Analisis dan Desain Sistem Informasi. Yogyakarta: Andi Offset.

Kristanto, Andri. (2010). Perancangan Sistem dan Aplikasi. Yogyakarta: Gava Media.

Kustiyaningsih, Yeni., R.A. Devie. (2011). Pemrograman Basis Data Berbasis Web Menggunakan PHP\& MySQL, Edisi Pertama. Yogyakarta: Graha Ilmu.

Loonam, J, dan Brady, M. (2010). Explorig the use of entity-relationship diagramming as a technique to support grounded theory inquiry. Bradford: Emerald Group Publishing.

Madcoms. (2011). Aplikasi Web Database Dengan Dreamweaver dan PHP-MySQL. Yogyakarta. Andi.

Mardiasmo. (2011). Analisa Perpajakan. Yogyakarta. Andi Offser.

Melati Suci Mayasari (2015). Analisa dan Perancangan Aplikasi Sistem Informasi Penggajian Karyawan pada PT Aditya Buana Inter Sungailiat Bangka. ISSN : 2252-4983, Volume 6, No. 2, Hal 277288.

Mujianto Adi, Dkk. (2014). Pelaksanaan pemborongan pekerjaan atau Outsourcing dalan perjanjian kerjasama antara PT Export Leaf Indonesia dengan Koperasi Lamina Berdasarkan Undang-Undang No.13 Tahun 2003 Tentang Ketenagakerjaan. ISSN: 1693-0819. Volume 08, No 02. Hal 32-40. 
Mustakini, Jogiyanto Hartono. 2010: Analisa Sistem Informasi, Edisi III. Yogyakarta: Andi.

Narbuko, Cholid dan Achmadi, Abu. (2013). Metodologi Penelitian. Jakarta: PT. Bumi Aksara.

Noor, Juliansyah. (2011). Metodologi Penelitian : Penelitian, Tesis, Disertasi, \& Karya Ilmiah. Jakarta: Kencana Prenada Media Group.

Pressman, Roger S. (2012). Rekayasa Perangkat Lunak Pendeketan Praktisi (Edisi 7). Yogyakarta. Andi.

Rudy Tantra. (2012). Manajemen Proyek Sistem Informasi. Andi Offset

Shalihin Miftah, dkk. (2014). Sistem Informasi Kepegawaian dan Gaji Madrasah Tsanawiyah Negeri (MTSN) 2 Simo Kab Boyolali. ISSN Print 1979-9330, ISSN Online 2088- 0154 Volume 6, No. 4Hal. $21-26$

Subhan, Mohamad. (2012). Analisis Perancangan Sistem. Jakarta: Lentera Ilmu Cendekia.

Sugiyono. (2013). Metode Penelitian Kuantitatif, Kualitatif, R\&D. Bandung: CV. Alfabeta.

Suharsaputra, Uhar. (2014). Metode Penelitian Kuantitatif, Kualitatif dan Tindakan. Bandung: PT. Refika Aditama.

Suharsimi, Arikunto. (2013). Prosedur Penelitian, Suatu Pendekatan Praktik. Jakarta: PT. Rineka Cipta.

Suratman. (2012). Pengantar Teknologi Informasi. Jakarta:Bumi Aksara.

Sutabri, Tata. (2012). Konsep Sistem Informasi. Yogyakarta. Andi Offset.

Yakub. (2012): Pengantar Sistem Informasi. Yogyakarta. Graha Ilmu.

Yustini. (2012). Buku Pengantar Teknologi Informasi. Yogyakarta: Bumi Aksara

Zulnalis, (2016). Sistem Informasi Penggajian Karyawan (Studi Kasus PT Arus Global Security Service

Jakarta). ISSN 2089-8711 Vol. V, No 2, Hal 206-211. KBBI: hhtps://kbbi.web.id [01 juni 2018]. Situs Dirjen Pajak: www.pajak.go.id [01 juni 2018] 